\title{
Advantageous Reservoir Characterization Technology in Extra Low Permeability Oil Reservoirs
}

\author{
Yutian Luo, ${ }^{1,2}$ Zhengming Yang, ${ }^{1,2}$ Lixin Meng, ${ }^{3}$ and Shutie $\mathrm{Li}^{2}$ \\ ${ }^{1}$ University of Chinese Academy of Sciences, Beijing 100190, China \\ ${ }^{2}$ PetroChina Research Institute of Petroleum Exploration \& Development, Langfang 065007, China \\ ${ }^{3}$ PetroChina Dagang Oilfield Company, Tianjin 300280, China
}

Correspondence should be addressed to Yutian Luo; luoyutian@petrochina.com.cn

Received 17 April 2017; Revised 22 August 2017; Accepted 7 September 2017; Published 12 October 2017

Academic Editor: Runcang Sun

Copyright (C) 2017 Yutian Luo et al. This is an open access article distributed under the Creative Commons Attribution License, which permits unrestricted use, distribution, and reproduction in any medium, provided the original work is properly cited.

\begin{abstract}
This paper took extra low permeability reservoirs in Dagang Liujianfang Oilfield as an example and analyzed different types of microscopic pore structures by SEM, casting thin sections fluorescence microscope, and so on. With adoption of rate-controlled mercury penetration, NMR, and some other advanced techniques, based on evaluation parameters, namely, throat radius, volume percentage of mobile fluid, start-up pressure gradient, and clay content, the classification and assessment method of extra low permeability reservoirs was improved and the parameter boundaries of the advantageous reservoirs were established. The physical properties of reservoirs with different depth are different. Clay mineral variation range is $7.0 \%$, and throat radius variation range is $1.81 \mu \mathrm{m}$, and start pressure gradient range is $0.23 \mathrm{MPa} / \mathrm{m}$, and movable fluid percentage change range is $17.4 \%$. The class IV reservoirs account for $9.56 \%$, class II reservoirs account for $12.16 \%$, and class III reservoirs account for $78.29 \%$. According to the comparison of different development methods, class II reservoir is most suitable for waterflooding development, and class IV reservoir is most suitable for gas injection development. Taking into account the gas injection in the upper section of the reservoir, the next section of water injection development will achieve the best results.
\end{abstract}

\section{Introduction}

China's extra low permeability reservoirs occurred with large quantity of geological resources and are generally characterized by poor reservoir properties [1]. Recently, low permeability has become the main drive in increasing reserves and production in China's petroleum industry [2]. Since 2007, the average annual proven low permeability reserve is 430 million tons for CNPC, accounting for $71.8 \%$ of the country, which are mainly extra low permeability reserves. The primary task of large scale development of low permeability reservoirs is comprehensive evaluation on reservoirs to determine the characteristics of advantageous reservoirs. Zhao et al. and Wenhui et al. carried out a comprehensive evaluation on reservoirs by using the seismic technique to predict lithology, sand bodies, physical properties, and hydrocarbon potential $[3,4]$. Zhengming et al. and Zhonghong et al. evaluated low permeability reservoir comprehensively by selecting abundance, effective thickness, throat radius, volume percentage of mobile fluid, start-up pressure gradient, and effective driving factors based on the characteristics of low permeability reservoirs [5], and then, based on optimization, they established a comprehensive reservoir evaluation method for low permeability oil regions by selecting five parameters, namely, throat radius, volume percentage of mobile fluid, start-up pressure gradient, clay content, and crude oil viscosity [6]. Jingjing et al. utilized the onsite exploitation indicators such as injection and production effectiveness analysis, water saturation profile analysis, and tracer analysis to determine the advantageous infiltration flow channels of reservoirs [7]. Amabeoku et al. proposed petrophysical data for reservoir evaluation [8]. Wilkes et al. evaluated the biodegradation of reservoir crude oil using stable carbon isotopes of specific mixtures. Bastia et al. analyzed the sedimentary history of the central and upper strata of the Bengal fan and the upper strata in the northeastern part of India and evaluated the potential of the deep-water reservoir [9]. 
McCaffrey and Kneller studied the potential process control of the development of the marginal stratigraphic traps in the narrow turbidite sedimentary system and its help in reservoir evaluation [10]. Al-Ghamdi et al. in the case of carbonate reservoirs in the Middle East have improved a triple-medium model to evaluate natural fractured reservoirs [11]. Chalmers and Bustin conducted a geological evaluation of the Triassic shale gas and dense gas mixed reservoirs in the Ground birch area of northeastern British Columbia, Canada [12]. Takahashi and Kovscek used surface tension to evaluate the wettability of low permeability siliceous shale [13].

The common reservoir evaluation methods in the literature are mainly used to evaluate oilfield blocks. Conventional methods using logging data cannot really characterize (accurate to meter) reservoir physical properties. There is a correlation between the individual parameters, and the evaluation results are biased. In this paper, the parameters are independent parameters, which represent the capacities of flow, development potential, supplementary energy, and water injection. A well in Dagang Oilfield is used as an example to establish the advantageous reservoirs characterization with the characteristics of evaluating the longitudinal distribution of reservoirs.

\section{Structural Features of Vertical Anisotropic Micropores in Extra Low Permeability Reservoirs}

Some interval in a well in Dagang Liujianfang Oilfield is taken as an example to illustrate the structural features of longitudinal heterogeneous micropores in the extra low permeability reservoirs. The well is located in a faulted nose retained by Gangxi fault and Gangdong fault, where small faults are developed. Shahejie Formation is the main reservoir with burial depth of around $2800-3800 \mathrm{~m}$. The physical properties of the reservoir are poor. It has an average porosity of $13.5 \%$ and an average permeability of $0.83 * 10^{-3} \mu \mathrm{m}^{2}$, with a recovery percent of reserves as low as only $1 \%-2 \%$. It was found from the production test results in the well that the interval of $3790.2-3792.7 \mathrm{~m}$ had poor effect, with only a small amount of produced fluid. No oil and gas were produced after multiple rounds of clean-ups. After clean-up in the interval of $3792.7-3808.0 \mathrm{~m}$, a gas show was found with some traces of oil. After fracturing, a natural flow was sustained. The preliminary stage daily oil production was $24.28 \mathrm{t}$ and the daily gas production was $5478 \mathrm{~m}^{3}$, and the relatively high yield was maintained all the time. Through the characterization of the advantageous reservoirs in the pay zone, it will help to understand the petrophysical parameters of the reservoirs and determine the difficulty degree of development and oil-recovery mode selection, thereby providing reliable scientific basis and technical assurance for highefficiency development of Liujianfang oilfield, while reducing development risks and improving economic benefit.

In this paper, the extra low permeability reservoirs in the well are taken as the research objects. The reservoirs are dominated by grayish brown sandstone intercalated with clay strips, and they have strong heterogeneity (Figure 1).
Therefore, the mean value of reservoir physical parameters cannot truly reflect the characteristics of physical properties of the reservoirs.

Select three pieces of cores from the depths of $3804.50 \mathrm{~m}$ (number 1 core), $3800.36 \mathrm{~m}$ (number 2 core), and $3797.46 \mathrm{~m}$ (number 3 core), respectively, to carry out scanning electron microscope (SEM) observation for the micropore structures of reservoirs, casting thin section test analysis for the development states of reservoir pores under different depths and fluorescence microsurvey analysis on oil saturated cores for oil distribution in different pore structures.

It can be found taking pictures of cores from different types of reservoirs under the scanning electron microscope (Figure 2) that the texture of number 1 core is loose and there are large size pores. It is indicated from the pictures of cores taken from the electron microscopy that the number of visible pores is about 12; casting thin sections show that the main pores of the cores are intergranular dissolution pores, intragranular dissolution pores, and moldic pores with good connectivity. It is indicated from the section fluorescence observation for oil saturated cores that the fluorescence intensity in the visual field is high, which indicates that the oil saturation is high. The oil is massively distributed and centralized. Areas with deep color and much water content are scarce. Number 2 core has relatively compact texture. It is indicated from the electron microscopic photos that the number of visible pores in number 2 core is about 8 ; casting thin sections show that the pores in the core are mainly intergranular dissolution pores with relatively good connectivity; it is indicated from the section fluorescence observation on oil saturated cores that the oil has silk-like and massive distribution, with some deep color much water containing areas. The electron microscopic photos of number 3 core show that there are some pores with a diameter of smaller than $10 \mu \mathrm{m}$; casting thin sections show that the pores are mainly intergranular pores with poor connectivity; according to the section fluorescence observation on the oil saturated cores, the fluorescence intensity in the visual field is relatively weak. The crude oil is centralized with asterisk shapes and there are large deep colored water contained areas with low oil saturation. It is indicated from the microphotos of cores that the pore structures of different depths in the same reservoir vary greatly, and the profiles of oil and water distribution in the reservoirs are not the same. Therefore, it is necessary to evaluate the reservoir in the longitudinal direction comprehensively.

\section{Evaluation Method of Advantageous Reservoirs in Extra Low Permeability Reservoirs}

3.1. Evaluation Parameters for Longitudinal Characteristics of Extra Low Permeability Reservoirs. The longitudinal physical properties of the extra low permeability reservoirs vary greatly. In order to characterize the characteristics of the physical properties of reservoirs, continuous tests are carried out for the petrophysical parameters of reservoirs in different depths to obtain the curves of various parameters changing 


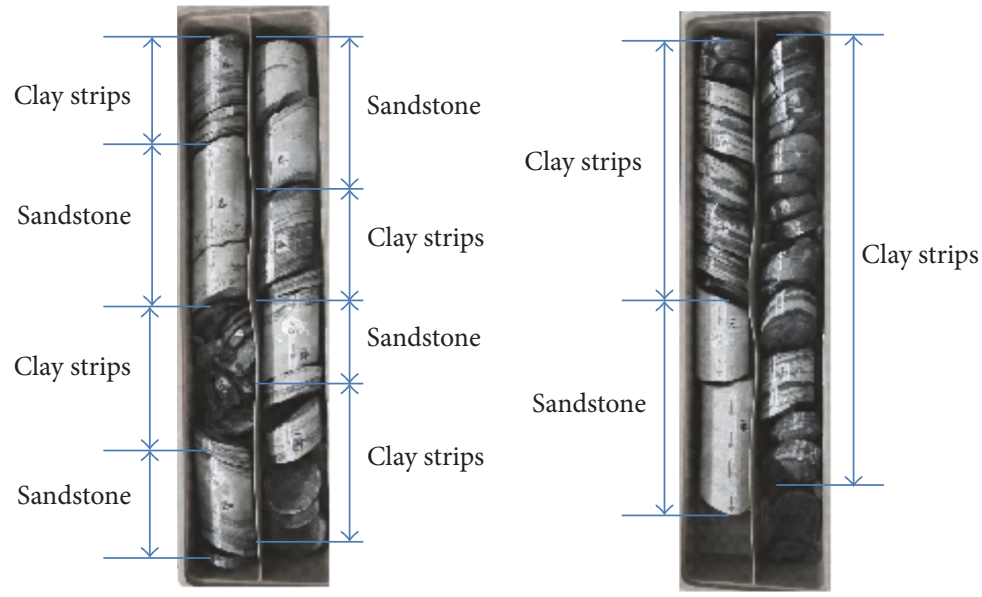

FIGURE 1: Full diameter core from a selected well.
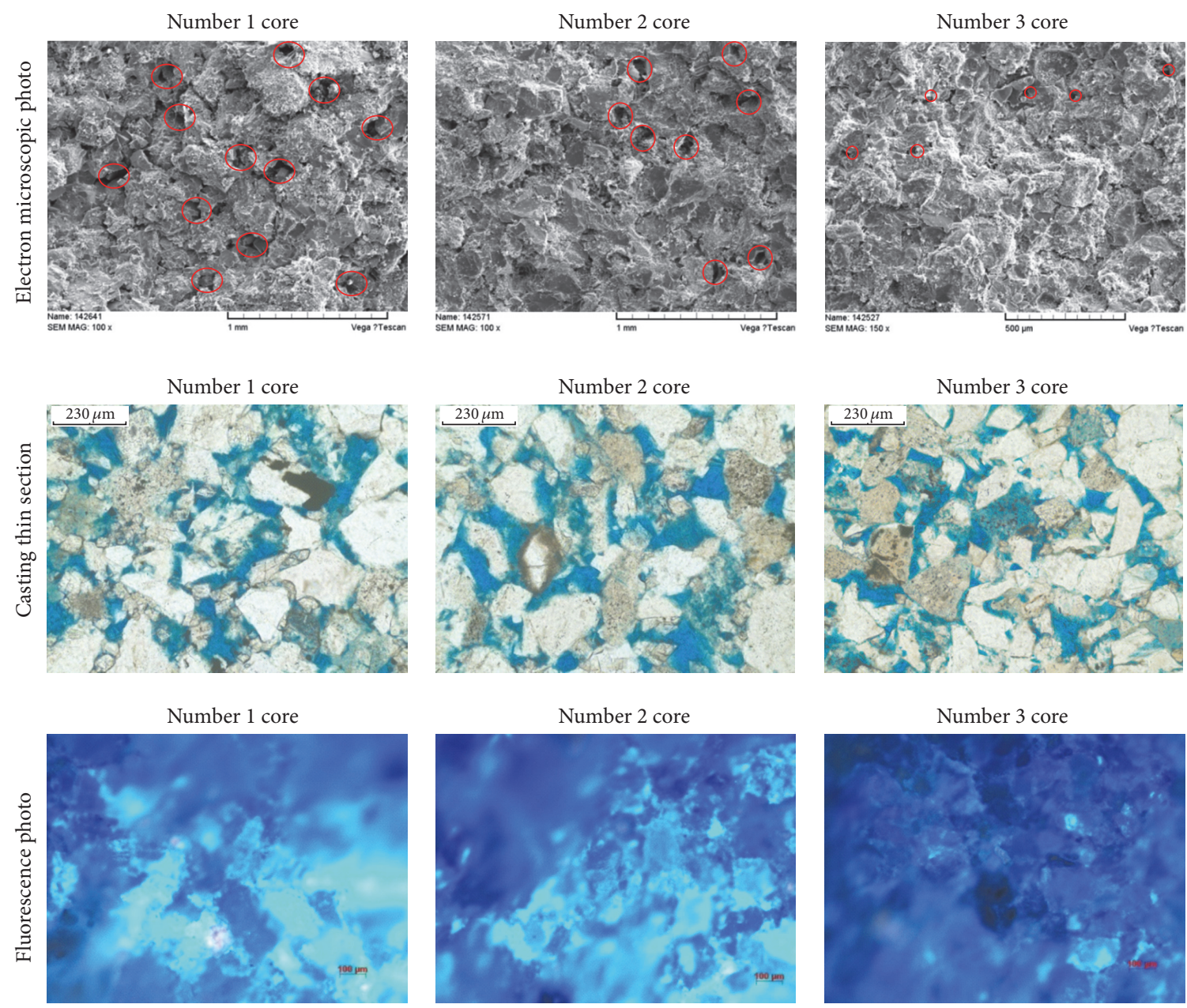

FIGURE 2: Microcosmic pore characteristics of different depths of reservoirs.

with depth, thereby determining the advantageous cores in a single well. In this paper, the extra low permeability cores from some well are taken as the research object. The full diameter cores are sampled evenly and continuously from the interval of $3794-3808 \mathrm{~m}$ to carry out porosity and permeability, clay mineral, throat radius, start-up pressure gradient, volume percentage of mobile fluid, and other parameter tests. And the longitudinal plates for various parameters are made as shown in Figure 3.

It is indicated from Figure 3 that the petrophysical parameters of the same reservoir are not single values, and there are significant differences among the petrophysical 


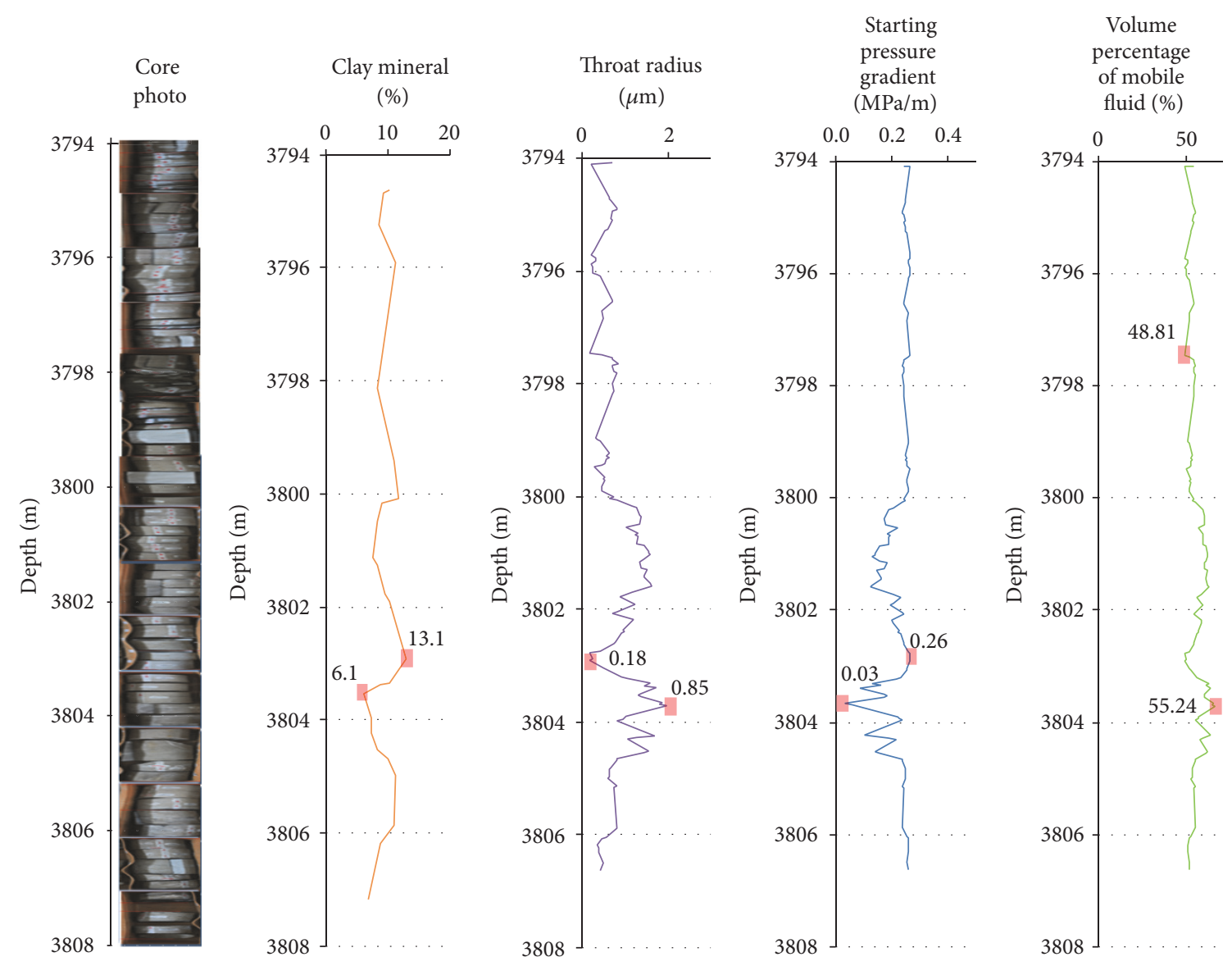

FIGURE 3: Curves of various petrophysical parameters changing with depth.

parameters of reservoirs in different depths. The contents of clay minerals are closely related to the difficulty of water flooding development [14-16]. The changes of clay mineral contents are the most intense in the well, which related to the heterogeneity of core components. The least clay content is $6.1 \%$, which occurs in the depth of $3803.5 \mathrm{~m}$; the most clay content is $13.1 \%$, which occurs in the depth of $3802.9 \mathrm{~m}$; the position with the minimum clay content and that with the maximum clay content are relatively close, indicating that there are major compositional variations in the reservoirs. The average clay content in the reservoirs is $9.4 \%$, and it is clear that using the average value to characterize the overall clay content in the reservoirs is not applicable. The size of the throat radius determines the ability of the reservoir fluid to flow $[17,18]$. The amplitude of variation of the throat radius in the reservoirs of the well is also large. The minimum value is $0.18 \mu \mathrm{m}$ at the depth of $3802.8 \mathrm{~m}$, and the maximum value is $1.99 \mu \mathrm{m}$ at the depth of $3803.7 \mathrm{~m}$. The average value in the reservoirs is $0.85 \mu \mathrm{m}$. The size of the start-up pressure gradient determines the spacing of the flooding pattern and the size of the water injection pressure [19-22]. The minimum start-up pressure gradient of the well is $0.03 \mathrm{MPa} / \mathrm{m}$ at the depth of $3803.6 \mathrm{~m}$ and the maximum value is $0.26 \mathrm{MPa} / \mathrm{m}$ at the depth of $3802.9 \mathrm{~m}$. The average value in the reservoirs is $0.22 \mathrm{MPa} / \mathrm{m}$. Volume percentage of mobile fluid decides the reservoir development potential [23-27]. The amplitude of variations in the volume percentage of mobile fluid in the well is small. The minimum value is $48.81 \%$ at the depth of $3797.5 \mathrm{~m}$ and the maximum value is $66.20 \%$ at the depth of $3803.7 \mathrm{~m}$. The average value of the reservoirs is $55.24 \%$. Each petrophysical parameter only represents the nature of one aspect of the reservoirs. In order to obtain the overall evaluation results of the reservoirs, a comprehensive evaluation on the reservoirs shall be carried out integrating multiple petrophysical parameters to determine the specific locations of various advantageous reservoirs.

3.2. Evaluation Method of Longitudinal Advantageous Reservoirs in Extra Low Permeability Reservoirs. In [5, 6], Reservoir's abundance, effective thickness, and throat radius, as well as the percentage of mobile fluid, start-up pressure gradient, and effective drive factor, are taken as the evaluating index. The multiparameter is used to evaluate the reservoir on the oilfield area, not used to locate advantageous reservoir. Reservoir abundance and effective thickness does not work when locating advantageous reservoir. The parameters which we selected represent the capacities of flow, development potential, supplementary energy, and water injection.

In this paper, four independent parameters, namely, clay mineral content, volume percentage of mobile fluid, throat 
TABLE 1: Boundaries of advantageous reservoir classification evaluation.

\begin{tabular}{lcccc}
\hline Reservoir classification & $\begin{array}{c}\text { Type I advantageous } \\
\text { reservoir }\end{array}$ & $\begin{array}{c}\text { Type II advantageous } \\
\text { reservoir }\end{array}$ & $\begin{array}{c}\text { Type III advantageous } \\
\text { reservoir }\end{array}$ & $\begin{array}{c}\text { Type IV advantageous } \\
\text { reservoir }\end{array}$ \\
\hline Boundary of evaluation & $1 \sim 2$ & $2 \sim 5$ & $5 \sim 8$ & $>8$ \\
\hline
\end{tabular}

radius, and start-up pressure gradient, are used to determine the locations of advantageous reservoirs. As there are no big compositional variations in the crude oil from the same reservoir, it is believed that the viscosity of the crude oil from the reservoirs is of a certain value. The comprehensive evaluation formula for the low permeability reservoirs is modified to get the advantageous reservoirs classification formula as follows:

$$
D=\ln \frac{\left(s / s_{0}\right)\left(r / r_{0}\right)}{\alpha\left(\lambda / \lambda_{0}\right)\left(m / m_{0}\right)},
$$

where $s$ is volume percentage of mobile fluid; $s_{0}$ is the calibration value of volume percentage of mobile fluid; $r$ is throat radius; $r_{0}$ is the calibration value of throat radius; $\lambda$ is the start-up pressure gradient; $\lambda_{0}$ is the calibration value of start-up pressure gradient; $m$ is clay mineral content; $m_{0}$ is the calibration value of clay mineral content; $D$ is the comprehensive evaluation parameter for advantageous reservoirs.

Based on the test results as shown in Figure 2, using the advantageous reservoir sorting computation formula, the comprehensive evaluation results for reservoirs with different depths can be obtained. The classification of advantageous reservoirs is obtained according to the evaluation limits of Table 1. From type I to Type III, the reservoir throat radius is larger, the movable fluid is more, the displacement pressure is smaller, and the water injection development is easier. Types I and II are easy to develop and waterflooding to add energy is easy. Type III: water injection to add energy is difficult, the general use of horizontal well volume modification and waterflooding to add energy. Type IV: the existing technology is extremely difficult to develop, the general use of horizontal well volume modification and gas injection to add energy.

It is indicated from Figure 4 that there are three types of advantageous reservoirs in the extra low permeability reservoirs, among which Type IV reservoirs which are hard to be developed account for 9.56\%; Type II reservoirs which can be easily developed account for $12.16 \%$; and Type III reservoirs for which researches shall be carried out for development account for $78.29 \%$. The overall porosity of the reservoir is not changed greatly, and the average porosity is $13.38 \%$. The permeability of the reservoirs varies greatly, among which the permeability in the intervals of 3800 $3802 \mathrm{~m}$ and $3803 \sim 3805 \mathrm{~m}$ is the highest. But there are Type IV reservoirs at the position of $3797.46 \mathrm{~m}$ with the corresponding permeability of $0.14 * 10^{-3} \mu \mathrm{m}^{2}$. The permeability at this position is higher than any of the nearby intervals. Type II and Type III reservoirs occur in the interval of $3800 \sim 3802 \mathrm{~m}$. Type II, Type, III and Type IV reservoirs even occur in the interval of $3803 \sim 3805 \mathrm{~m}$, indicating that there is no certain correlation between the classification of reservoirs with extra low permeability and permeability.

\section{Study on the Development Methods of Longitudinal Seepage Channels in Extra Low Permeability Reservoirs}

Taking a well in Dagang Oilfield as an example, a total of 12 pieces of cores are taken to carry out water flooding and gas flooding development method studies for different types of reservoirs. Oil and water phase-permeability and oil and gas phase-permeability tests are carried out for three types of reservoirs. Comparing the flooding efficiency under two experimental conditions, the development modes suitable for every type of reservoirs are optimized.

4.1. Water Flooding Development Mode Study. It is indicated from the experimental results (Table 2) of oil and water phase-permeability that the average bound water in Type IV reservoirs is $52.36 \%$, and the average remaining oil saturation is $24.02 \%$. From the residual oil fluorescence photograph (Figure 5), it can be seen that there is still relatively rich crude oil. The range of the common percolation area of two phases is the narrowest, indicating that the seepage capability is the weakest, where water flooding development is difficult, and the ultimate average flooding efficiency is $53.56 \%$. The average bound water in Type III reservoirs is $48.29 \%$, and there is little residual oil, where water flooding development is relatively easy, and the ultimate flooding efficiency is $62.79 \%$. The average bound water in Type II reservoirs is $47.89 \%$ and there is very little residual oil. It is indicated from the fluorescence photos that there is a small amount of crude oil. The common percolation area of two phases is the widest, indicating that the seepage capability is the strongest. It is suitable for water flooding development. The ultimate flooding efficiency is $67.24 \%$. The advantageous seepage channels for water flooding development are concentrated in Type II reservoirs. The larger the water phase-permeability is, the more favorable it is for water flooding development. When carrying out fracturing stimulation in the reservoirs, the emphasis should be laid on Type III reservoirs and Type IV reservoirs for carrying out hydraulic fracturing, thereby improving the flow capacity of reservoirs to make the displacement front evenly advanced.

4.2. Gas Flooding Development Mode Study. It is indicated from the oil and gas phase-permeability experimental results (Table 3) that the average residual oil in Type IV reservoirs is $8.49 \%$. Only a small amount of residual oil can be seen in the fluorescence photo (Figure 6). The width of the common percolation area is $42.70 \%$, and the average ultimate flooding efficiency is $83.44 \%$, indicating that gas flooding is the optimal development mode for this type of reservoirs. The average residual oil in Type III reservoirs is $20.74 \%$, the 

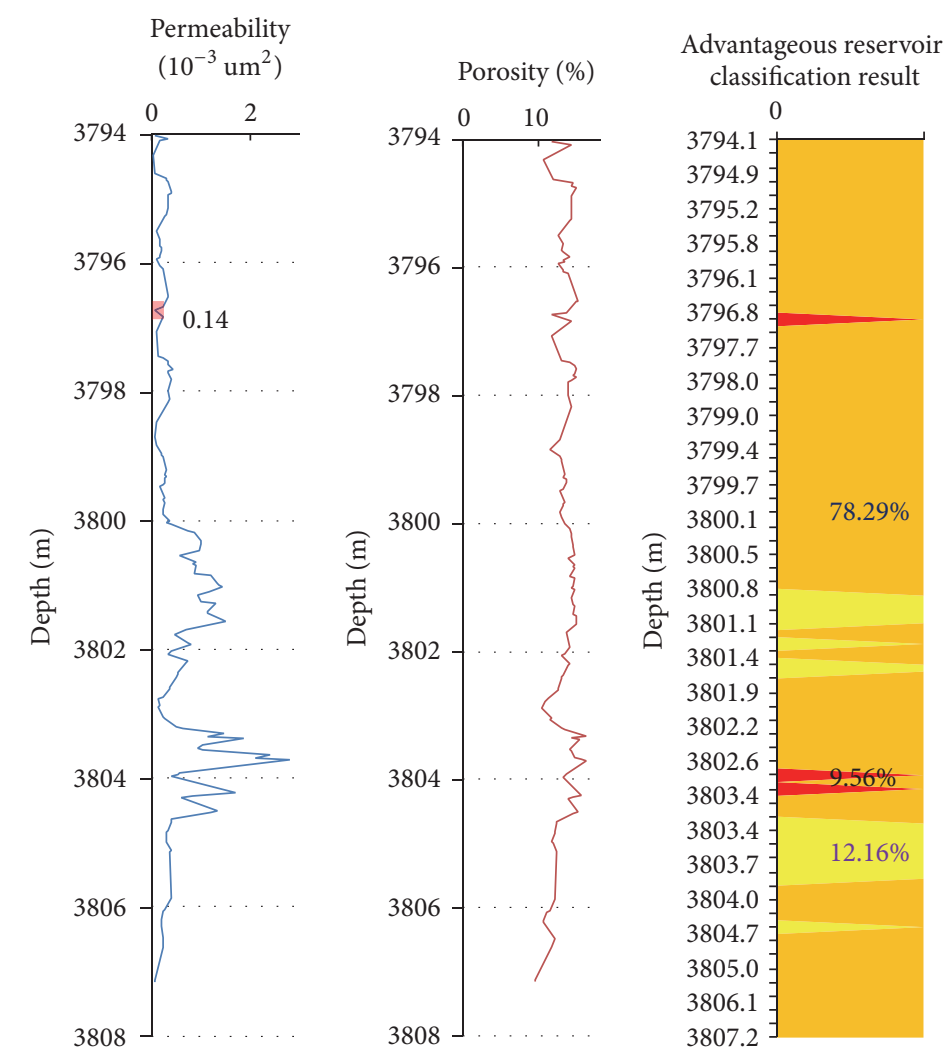

I type reservoir II type reservoir

III type reservoir

IV type reservoir

FIGURE 4: Comparison chart between advantageous reservoirs, porosity, and permeability.

TABLE 2: Oil and water phase-permeability test data of three types of reservoirs.

\begin{tabular}{|c|c|c|c|c|c|}
\hline Reservoir type & $\begin{array}{c}\text { Bound water } \\
\text { saturation (\%) }\end{array}$ & $\begin{array}{l}\text { Remaining oil } \\
\text { saturation (\%) }\end{array}$ & $\begin{array}{l}\text { Width of common } \\
\text { percolation area (\%) }\end{array}$ & $\begin{array}{c}\text { Common percolation } \\
\text { point water saturation }(\%)\end{array}$ & $\begin{array}{l}\text { Flooding efficiency } \\
\qquad \%) \\
\end{array}$ \\
\hline \multirow{2}{*}{ Type IV reservoir } & $52.27 \%$ & $25.36 \%$ & $26.36 \%$ & $58.49 \%$ & $50.97 \%$ \\
\hline & $52.46 \%$ & $22.67 \%$ & $29.03 \%$ & $54.77 \%$ & $56.15 \%$ \\
\hline Average & $52.37 \%$ & $24.02 \%$ & $27.70 \%$ & $56.63 \%$ & $53.56 \%$ \\
\hline \multirow{2}{*}{ Type III reservoir } & $48.28 \%$ & $19.34 \%$ & $28.39 \%$ & $65.55 \%$ & $59.48 \%$ \\
\hline & $48.30 \%$ & $16.12 \%$ & $31.42 \%$ & $59.70 \%$ & $66.10 \%$ \\
\hline Average & $48.29 \%$ & $17.73 \%$ & $29.91 \%$ & $62.63 \%$ & $62.79 \%$ \\
\hline \multirow{2}{*}{ Type II reservoir } & $47.74 \%$ & $18.17 \%$ & $34.09 \%$ & $63.92 \%$ & $65.24 \%$ \\
\hline & $48.04 \%$ & $15.99 \%$ & $35.97 \%$ & $64.51 \%$ & $69.23 \%$ \\
\hline Average & $47.89 \%$ & $17.08 \%$ & $35.03 \%$ & $64.22 \%$ & $67.24 \%$ \\
\hline
\end{tabular}

average width of the common percolation area is $31.05 \%$, and the ultimate flooding efficiency is differentiated ranging from $47.17 \%$ to $72.89 \%$, indicating that gas channeling occurred during the experiment. Ideal effect can be hardly achieved using the gas flooding mode for this type of reservoirs. The average of residual oil of Type II reservoirs is $27.80 \%$. It is indicated from the fluorescence photos that much crude oil is left and the average width of the common percolation area is $24.70 \%$. The ultimate flooding efficiency is only $47.07 \%$.
The effect of the gas flooding development mode is poor. The larger the gas-phase-permeability is, the easier it is for causing fingering and gas channeling. Type II and Type III reservoirs are not conducive to gas flooding development. The gas flooding development mode shall be considered for the upper horizons of the well, and the water flooding development mode shall be adopted for the lower interval horizons of the well. The combination of the two development methods will achieve the best results. 

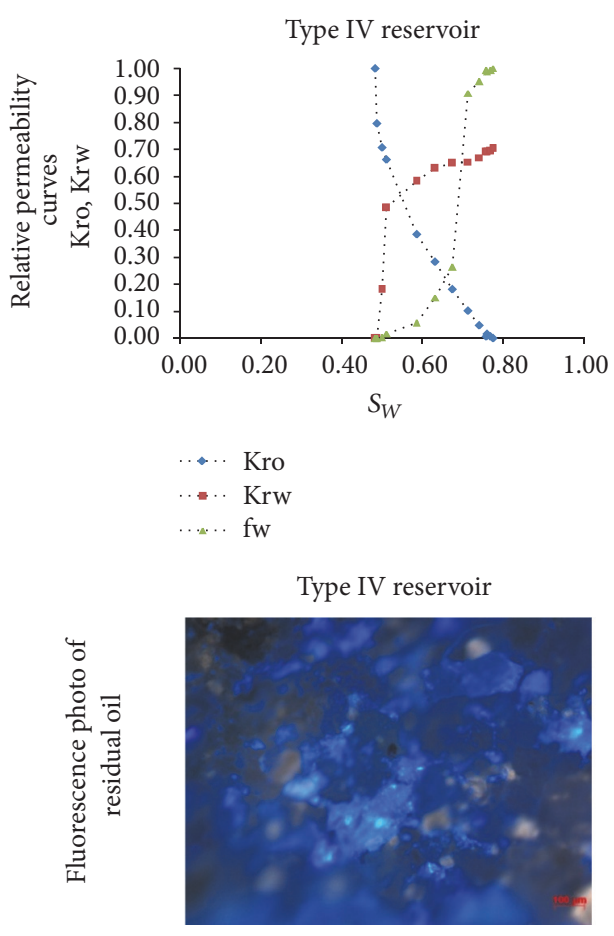

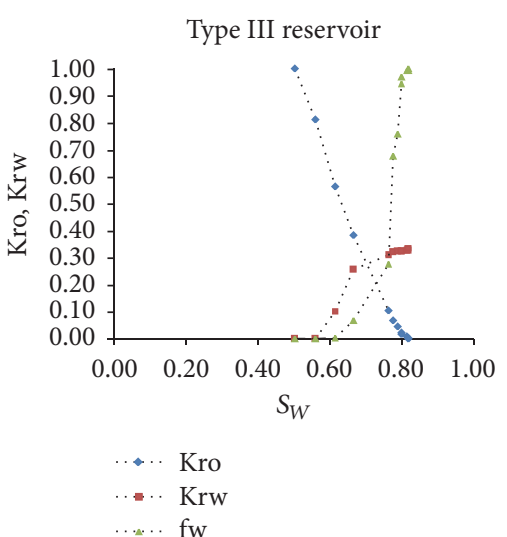

Type III reservoir

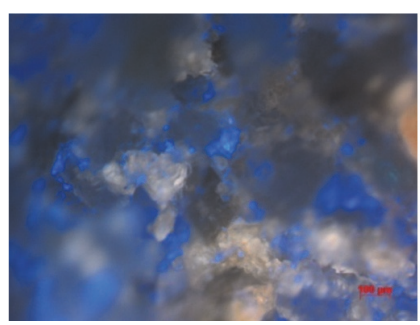

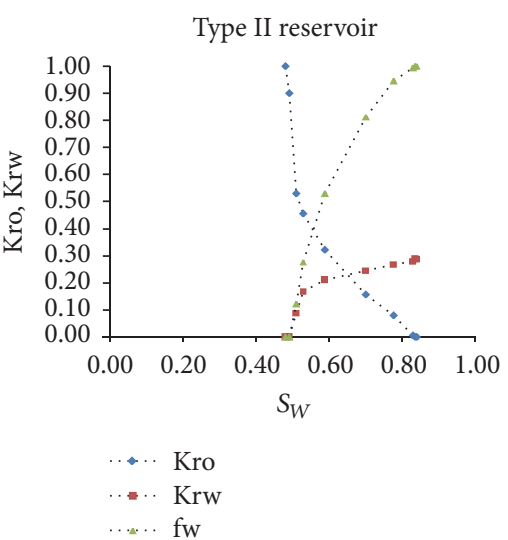

Type II reservoir

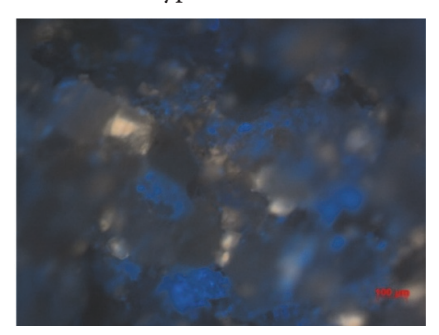

FIGURE 5: Curves of oil and water phase-permeability in three types of reservoirs and photos of residual oil.

TABLE 3: Oil and gas phase-permeability test data of three types of reservoirs.

\begin{tabular}{|c|c|c|c|c|c|c|}
\hline Number & $\begin{array}{l}\text { Bound water } \\
\text { saturation (\%) }\end{array}$ & $\begin{array}{l}\text { Ultimate gas } \\
\text { saturation (\%) }\end{array}$ & $\begin{array}{l}\text { Remaining oil } \\
\text { saturation (\%) }\end{array}$ & $\begin{array}{c}\text { Width of common } \\
\text { percolation area } \\
(\%)\end{array}$ & $\begin{array}{c}\text { Common } \\
\text { percolation point } \\
\text { gas saturation }(\%)\end{array}$ & $\begin{array}{l}\text { Flooding efficiency } \\
\qquad \%)\end{array}$ \\
\hline \multirow{2}{*}{$\begin{array}{l}\text { Type IV } \\
\text { reservoir }\end{array}$} & $49.05 \%$ & $43.90 \%$ & $7.05 \%$ & $43.90 \%$ & $34.40 \%$ & $86.16 \%$ \\
\hline & $48.58 \%$ & $41.50 \%$ & $9.92 \%$ & $41.50 \%$ & $26.15 \%$ & $80.72 \%$ \\
\hline Average & $48.82 \%$ & $42.70 \%$ & $8.49 \%$ & $42.70 \%$ & $30.28 \%$ & $83.44 \%$ \\
\hline \multirow{2}{*}{$\begin{array}{l}\text { Type III } \\
\text { reservoir }\end{array}$} & $48.41 \%$ & $37.60 \%$ & $13.99 \%$ & $37.60 \%$ & $19.95 \%$ & $72.89 \%$ \\
\hline & $48.06 \%$ & $24.50 \%$ & $27.44 \%$ & $24.50 \%$ & $13.95 \%$ & $47.17 \%$ \\
\hline Average & $48.24 \%$ & $31.05 \%$ & $20.72 \%$ & $31.05 \%$ & $16.95 \%$ & $60.03 \%$ \\
\hline \multirow{2}{*}{$\begin{array}{l}\text { Type II } \\
\text { reservoir }\end{array}$} & $47.84 \%$ & $25.40 \%$ & $26.76 \%$ & $25.40 \%$ & $15.25 \%$ & $48.70 \%$ \\
\hline & $47.17 \%$ & $24.00 \%$ & $28.83 \%$ & $24.00 \%$ & $17.05 \%$ & $45.43 \%$ \\
\hline Average & $47.51 \%$ & $24.70 \%$ & $27.80 \%$ & $24.70 \%$ & $16.15 \%$ & $47.07 \%$ \\
\hline
\end{tabular}

\section{Conclusion}

In this paper, the longitudinal interval with extra low permeability reservoirs in a well in Dagang Oilfield is taken as an example, and elaborate characterization is carried out for the micropore structures of the cores using scanning electron microscope (SEM), casting thin section, fluorescence microscopy, and other technologies. Classification evaluation is carried out for advantageous reservoirs integrating clay mineral, throat radius, mobile fluid, starting pressure, and other petrophysical parameter indicators. The advantageous seepage channels of the reservoirs are determined using the oil and water and oil and gas phase-permeability experiments and photos of residual oil to form the extra low permeability advantageous reservoir characterization from cores to reservoirs, and then to single wells.

(1) The structural features of longitudinal heterogeneous micropores in the extra low permeability reservoirs are compared. The physical properties of different depths are different. Electron microscopy shows that the pore diameter is distributed from $10 \mu \mathrm{m}$ to $100 \mu \mathrm{m}$. Good physical properties of the core fluorescence were shown to be strong and poor physical properties of the core fluorescence were shown to be weak. Using the mean value of single petrophysical parameters to measure the reservoir properties is no longer applicable.

(2) Through clay mineral content, throat radius, volume percentage of mobile fluid, and start-up pressure gradient 

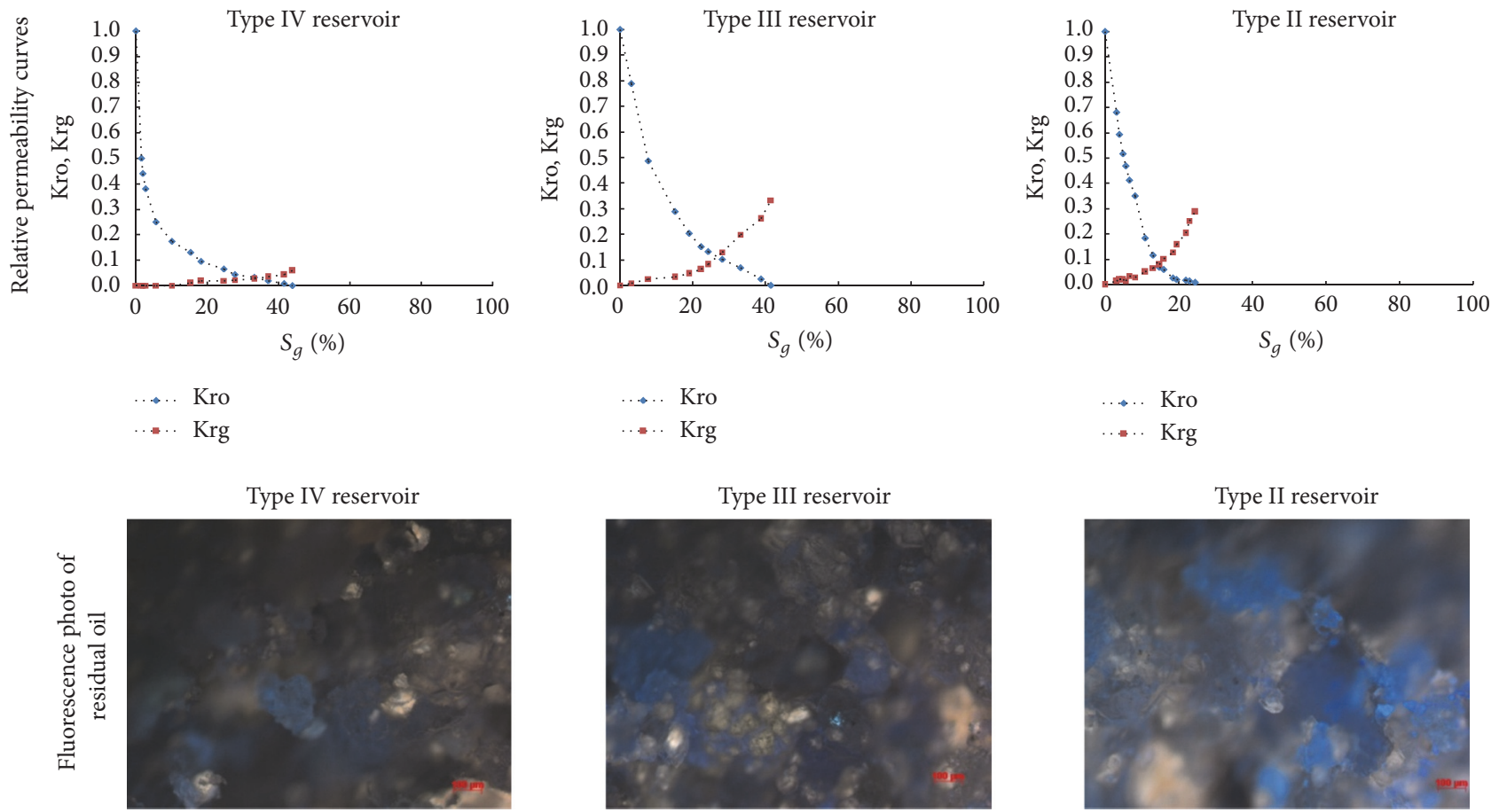

FIGURE 6: Curves of oil \& gas phase-permeability in three types of reservoirs and photos of residual oil.

tests for single well cores from extra low permeability reservoirs, the curves of various petrophysical parameters changing with the depth of reservoirs are established. The single porosity and permeability values are no longer indicative of reservoir characteristics. The reservoirs were identified by longitudinal comprehensive evaluation of reservoirs. The reservoir IV reservoirs account for 9.56\%, Type II reservoirs account for $12.16 \%$, and Class III reservoirs account for $78.29 \%$.

(3) The advantageous seepage channels of the reservoirs are determined using the phase-permeability experiments and residual oil fluorescence photos. The ranges of water flooding efficiency changes of the three types of reservoirs are smaller than those of the gas flooding efficiency. The water flooding efficiency of Type II advantageous reservoirs is $67.24 \%$, and the most suitable development mode is water flooding. The gas flooding efficiency of Type IV advantageous reservoirs is $83.44 \%$, and the gas flooding development mode is the optimal. But when carrying out gas flooding development in Type II and Type III advantageous reservoirs, gas channeling is likely to be caused. According to the experimental results and proportions of various advantageous reservoirs, the gas flooding development mode may be adopted for the upper interval of the reservoirs and the water flooding development mode for the lower interval of the reservoirs in the well of Dagang Oilfield, and the combination of the two development methods can achieve the best effect.

\section{Conflicts of Interest}

The authors declare that they have no conflicts of interest.

\section{References}

[1] Z. Guangming and G. Weiliang, Petroleum Geology of China, Petroleum Industry Press, Beijing, China, 2005.

[2] H. Wenrui, "The present and future of low permeability of oil and gas in China," Engineering Sciences, vol. 11, no. 8, pp. 29-37, 2009.

[3] X. Zhao, Q. Wang, F. Jin et al., "Re-exploration program for petroleum-rich sags and its significance in Bohai Bay Basin, East China," Petroleum Exploration and Development, vol. 42, no. 6, pp. 790-801, 2015.

[4] X. Wenhui, X. Wenjun, G. Wenzhong et al., "Research on prediction technology for favorable reservoir in Sha-1 member in nanpu oilfield," Special Oil and Gas Reservoirs, vol. 21, no. 4, pp. 70-73, 2014.

[5] Y. Zhengming, Z. Yingzhi, H. Mingqiang et al., "Comprehensive evaluation of reservoir in low permeability oilfields," Acta Petrolei Sinica, vol. 27, no. 2, pp. 64-67, 2006.

[6] Z. Zhonghong, Y. Zhengming, L. Xiangui et al., "Yang Zhengming, Liu Xiangui," Acta Petrolei Sinica, vol. 33, no. 3, pp. 437441, 2012.

[7] G. Jingjing, T. Xiaoyun, C. Hua et al., "The characters of preferential seepage channel and remaining oil distribution in the meandering-river reservoir," Journal of Oil and Gas Technology, vol. 36, no. 7, pp. 117-121, 2014.

[8] M. O. Amabeoku, D. G. Kersey, R. H. BinNasser, and H. H. Mohammadi, "Strategies for acquiring and integrating petrophysical data for reservoir evaluation," in Proceedings of the SPE Annual Technical Conference and Exhibition, SPE 125169, 2009.

[9] H. Wilkes, A. Vieth, and R. Elias, "Constraints on the quantitative assessment of in-reservoir biodegradation using compound-specific stable carbon isotopes," Organic Geochemistry, vol. 39, no. 8, pp. 1215-1221, 2008. 
[10] W. McCaffrey and B. Knelle, "Process controls on the development of stratigraphic trap potential on the margins of confined turbidite systems and aids to reservoir evaluation," $A A P G$ Bulletin, vol. 85, no. 6, pp. 971-988, 2001.

[11] A. Al-Ghamdi, B. Chen, H. Behmanesh, F. Qanbari, and R. Aguilera, "An improved triple-porosity model for evaluation of naturally fractured reservoirs," in Proceedings of the Trinidad and Tobago Energy Resources Conference, SPE132879, pp. 397404, 2011.

[12] G. R. Chalmers and R. M. Bustin, "Geological evaluation of Halfway-Doig-Montney hybrid gas shale-tight gas reservoir, northeastern British Columbia," Marine and Petroleum Geology, vol. 38, no. 1, pp. 53-72, 2012.

[13] S. Takahashi and A. R. Kovscek, "Wettability estimation of lowpermeability, siliceous shale using surface forces," Journal of Petroleum Science and Engineering, vol. 75, no. 1-2, pp. 33-43, 2010.

[14] Z. Daqian and L. Shuzhen, "Types and characteristics of low permeability sandstone reservoirs in China," Acta Petrolei Sinica, vol. 15, no. 1, pp. 38-46, 1994.

[15] P. Shimi, X. Yin, Z. Jichun et al., "Evolutionary pattern of clay mineral and rock sensitivity in water-flooding reservoir," Acta Petrolei Sinica, vol. 27, no. 4, pp. 71-75, 2006.

[16] M. O. Okuyiga, A. Berrim, S. S. Haddad, C. Xian, and M. S. Abu Lawi, "Multidisciplinary approach and new technology improves carbonate reservoir evaluation," in Proceedings of the International Petroleum Technology Conference, Dubai, UAE, 2007.

[17] W. Xuewu, Y. Zhengming, L. Xiaxia et al., "Micro pore structure in extra-low permeability reservoir of Yushulin Oilfield," Journal of Oil and Gas Technology, vol. 30, no. 2, pp. 508-510, 2008.

[18] C. Clarkson, J. Jensen, and S. Chipperfield, "Unconventional gas reservoir evaluation: What do we have to consider?" Journal of Natural Gas Science and Engineering, vol. 8, pp. 9-33, 2012.

[19] Y. Zhengming, Y. Rongze, S. Zhixin et al., "Numerical simulation of the nonlinear flow in extra-low permeability reservoirs," Petroleum Exploration and Development, vol. 37, no. 1, pp. 9498, 2010.

[20] Y. Shi, Y. Zhengming, and H. Yanzhang, "Study on nonlinear seepage flow model for low-permeability reservoir," Acta Petrolei Sinica, vol. 30, no. 5, pp. 731-734, 2009.

[21] L. Yubao, Y. Qingyan, and L. Xiangui, “Three-phase seepage characteristics of oil, gas and water in low permeability reservoirs," Acta Petrolei Sinica, vol. 27, no. S, pp. 124-128, 2006.

[22] T. Pfeiffer, V. Kretz, D. Opsen, V. Achourov, and O. Mullins, "Fluid profiling for reservoir evaluation - two norwegian case studies," in Proceedings of the SPE Annual Technical Conference and Exhibition, SPE 166204, New Orleans, LO, USA.

[23] Y. Zhengming, M. Sheng, L. Xiangui et al., "Percentage parameter of the movable fluid in extra-low permeability reservoir and its application," Journal of Xian Petroleum University: Natural Science Edition, vol. 22, no. 2, pp. 96-99, 2007.

[24] W. Weimin, G. Hekun, and Y. Zhaohui, "The Evaluation of development potential in low permeability oilfield by the aid of NMR movable fluid detecting technology," Acta Petrolei Sinica, vol. 22, no. 6, pp. 40-44, 2001.

[25] L. Yutian, Y. Zhengming, H. Ying et al., "The research of lithology characteristics and effective development in tight oil reservoir," Unconventional Oil \& Gas, vol. 1, no. 1, pp. 47-54, 2014.
[26] C. Zhang, L. Xiao, Z. Mao, Z. Sun, and X. Luo, "A novel method to construct capillary pressure curves by using NMR log data and its application in reservoir evaluation, SPE 126735," in Proceedings of the Kuwait International Petroleum Conference and Exhibition, Kuwait City, Kuwait, 2009.

[27] R. J. Marchel, C. H. Smith, and S. Ramakrishna, "Utilizing simultaneous capture of T1 and T2 NMR data to solve reservoir evaluation issues," in Proceedings of the Asia Pacific Oil and Gas Conference \& Exhibition, Jakarta, Indonesia, 2009. 


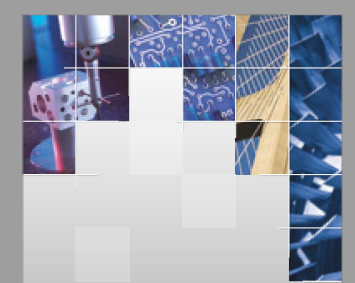

\section{Enfincering}
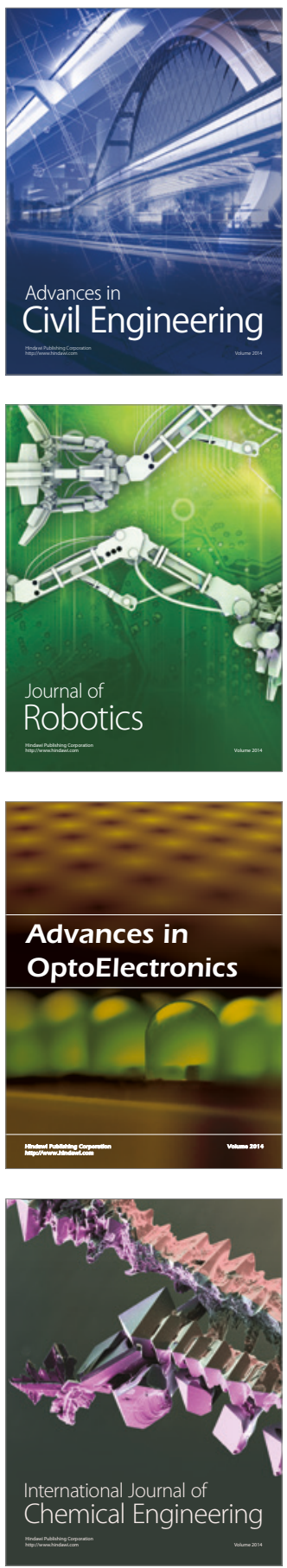

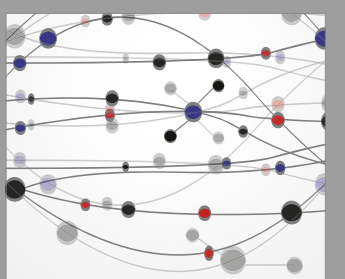

The Scientific World Journal

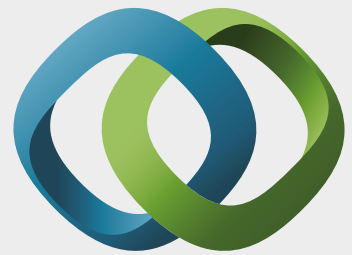

\section{Hindawi}

Submit your manuscripts at

https://www.hindawi.com
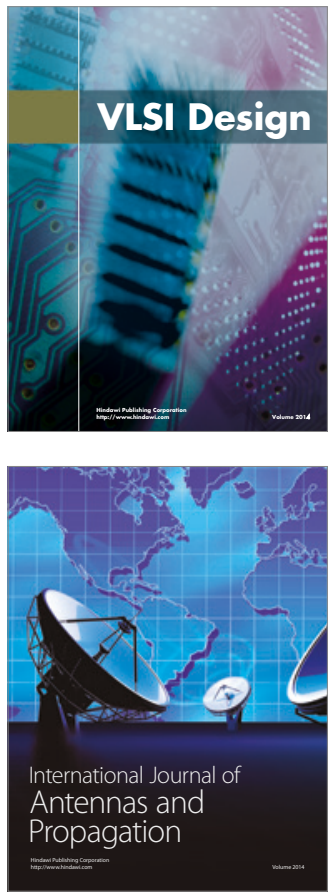

\section{Rotating}

Machinery
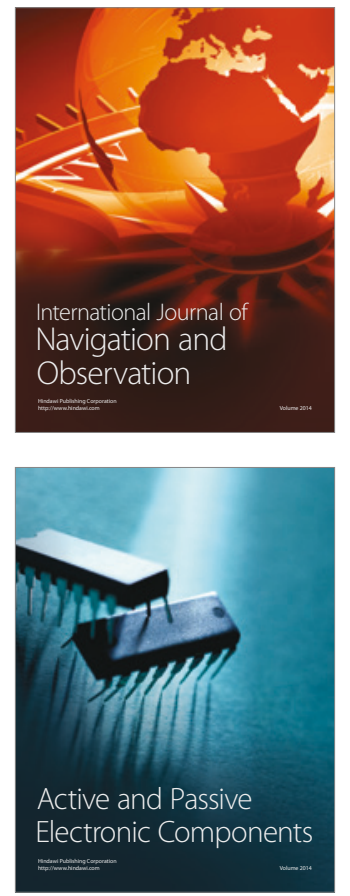
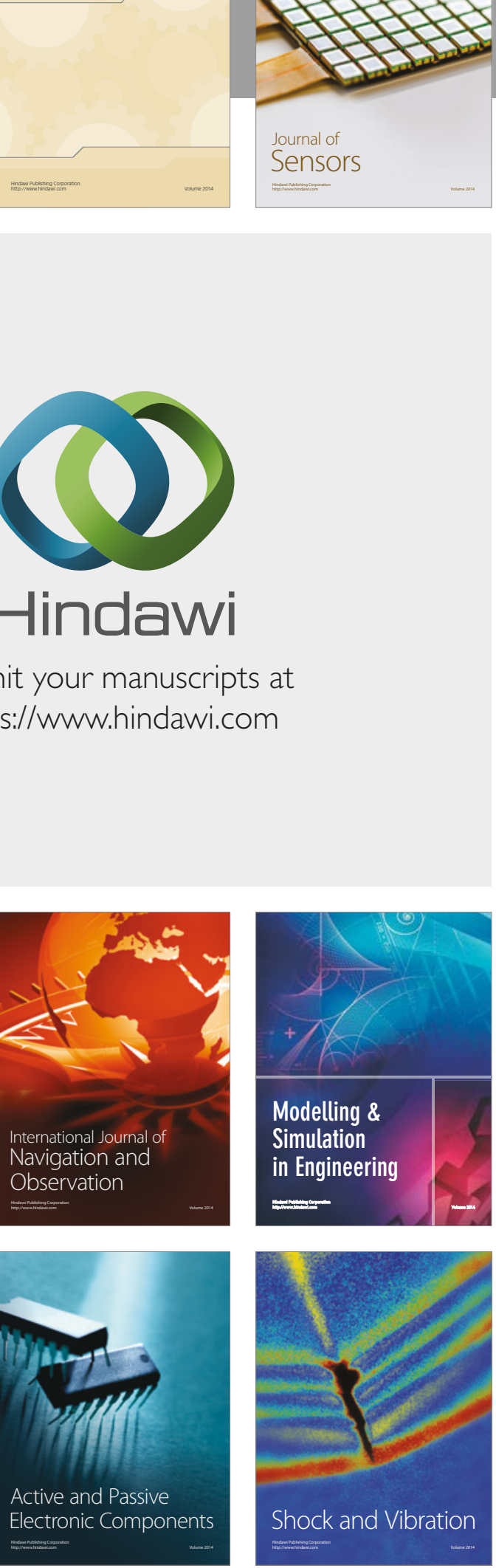
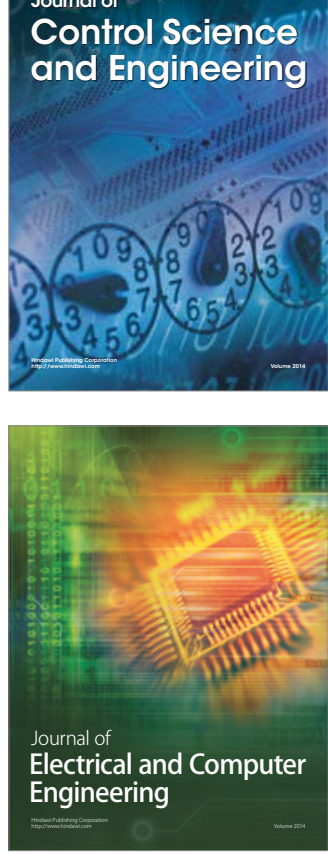

Distributed

Journal of

Control Science

and Engineering
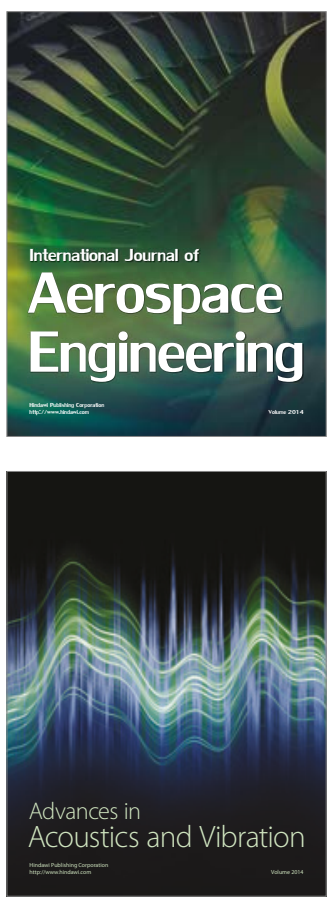

Sensor Networks 